\title{
Sarcopenia and change in body composition following maximal androgen suppression with abiraterone in men with castration- resistant prostate cancer
}

\author{
C Pezaro ${ }^{1,2}$, D Mukherji ${ }^{1,2}$, N Tunariu ${ }^{1}$, A M Cassidy ${ }^{1}$, A Omlin ${ }^{1}$, D Bianchini ${ }^{1}$, G Seed $^{1}$, A H M Reid ${ }^{1}$, \\ D Olmos ${ }^{1}$, J S de Bono ${ }^{1,3}$ and G Attard ${ }^{\star, 1,3}$
}

${ }^{1}$ Prostate Cancer Targeted Therapy Group and Drug Development Unit, The Royal Marsden NHS Foundation Trust and The Institute of Cancer Research, Downs Road, Sutton, Surrey, UK

Background: Standard medical castration reduces muscle mass. We sought to characterize body composition changes in men undergoing maximal androgen suppression with and without exogenous gluocorticoids.

Methods: Cross-sectional areas of total fat, visceral fat and muscle were measured on serial CT scans in a post-hoc analysis of patients treated in Phase I/II trials with abiraterone followed by abiraterone and dexamethasone $0.5 \mathrm{mg}$ daily. Linear mixed regression models were used to account for variations in time-on-treatment and baseline body mass index (BMI).

Results: Fifty-five patients received a median of 7.5 months abiraterone followed by 5.4 months abiraterone and dexamethasone. Muscle loss was observed on single-agent abiraterone (maximal in patients with baseline BMI > 30, - 4.3\%), but no further loss was observed after addition of dexamethasone. Loss of visceral fat was also observed on single-agent abiraterone, (baseline BMI $>30$ patients $-19.6 \%$ ). In contrast, addition of dexamethasone led to an increase in central visceral and total fat and BMI in all the patients.

Interpretation: Maximal androgen suppression was associated with loss of muscle and visceral fat. Addition of low dose dexamethasone resulted in significant increases in visceral and total fat. These changes could have important quality-of-life implications for men treated with abiraterone.

Androgens, together with growth hormone mimetics and follistatin, activate anabolic pathways in a process that results in the accrual of muscle mass (Basaria and Bhasin, 2012). Androgens are therefore an important determinant of body composition in men. In fact, serum testosterone concentrations correlate positively with muscle and negatively with fat mass (Vermeulen et al, 1999). A change in body composition, with loss of muscle mass and increased subcutaneous and visceral abdominal fat, is widely recognised as an adverse effect of castration for men with prostate cancer (Lee et al, 2005; Hamilton et al, 2011; Smith et al, 2012). Skeletal muscle depletion is associated with reduced functional ability and increased mortality (Fearon et al, 2011) and may also contribute to the increased cardio-metabolic risk associated with androgen-deprivation therapy (Basaria and Bhasin, 2012). Testosterone levels decline from $>50 \mathrm{ng} \mathrm{dl}^{-1}$ to a median of $7 \mathrm{ng} \mathrm{dl}^{-1}$ following castration for prostate cancer (Attard et al, 2008; Ryan

\footnotetext{
${ }^{*}$ Correspondence: Dr G Attard; E-mail: gerhardt.attard@icr.ac.uk

${ }^{2}$ These authors contributed equally as first authors.

${ }^{3}$ Co-senior authors.
} 
et al, 2010). Treatment of castration-resistant prostate cancer (CRPC) with abiraterone, a selective inhibitor of CYP17A1, results in a further decline in serum testosterone to $<0.9 \mathrm{ng} \mathrm{dl}^{-1}$ (Attard et al, 2012). A decline in cortisol associated with a compensatory rise in adrenocorticotrophic hormone and a consequent syndrome of secondary mineralocorticoid excess in most patients treated with abiraterone alone has led to its development in combination with exogenous glucocorticoids, most commonly prednisone $5 \mathrm{mg}$ bid.

Abiraterone improves the survival of men with docetaxeltreated and chemotherapy-naive CRPC (de Bono et al, 2011; Ryan et al, 2013). As abiraterone is better tolerated than chemotherapy, it is anticipated that it will be increasingly widely used before chemotherapy. A change in body composition with abiraterone could have important implications for the quality of life of men with advanced prostate cancer, especially men who are asymptomatic or minimally symptomatic. If recognized, body composition changes can be addressed through exercise interventions (Segal et al, 2003; Galvao et al, 2010). We hypothesized that both abiraterone and exogenous glucocorticoids could affect body composition, and we therefore separately evaluated the effects of abiraterone alone (resulting in 'super-castrate' levels of serum androgens) and after addition of exogenous glucocorticoids to abiraterone in men with progressive CRPC.

\section{MATERIALS AND METHODS}

Patients. All patients treated with single-agent abiraterone in clinical trials at the Royal Marsden NHS Foundation Trust, UK (COU-AA-001 (Attard et al, 2009), COU-AA-003 (Reid et al, 2010) and COU-Bioequivalence (Carden et al, 2008)) were considered for this post-hoc analysis. Entry to these trials required histological evidence of prostate adenocarcinoma with progressing disease by Prostate Working Group criteria (Bubley et al, 1999), adequate bone marrow, renal and hepatic function and good performance status; without brain metastases, spinal cord compression, uncontrolled hypertension or serious concurrent medical illness. All patients maintained a castrate state throughout study participation by means of ongoing LHRH analogue therapy or surgical castration. These trials allowed addition of dexamethasone $0.5 \mathrm{mg}$ daily at PSA progression on abiraterone alone or for management of abiraterone-related toxicity. Dexamethasone was utilized in preference to prednisone due to higher activity reported in CRPC (Venkitaraman et al, 2008), less mineralocorticoid activity (Lan et al, 1982) and to evaluate re-induction of sensitivity to abiraterone in patients who had been previously treated with the same dose and regimen of glucocorticoid (Attard et al, 2009). Patients were not provided specific instructions about nutrition or exercise. Study protocols were approved by the Royal Marsden institutional research board (IRB), and all patients provided informed consent for imaging and data collection.

Study design. The primary outcome of this analysis was change of muscle, subcutaneous fat, visceral fat and total fat area and of body mass index (BMI) after a minimum of 6 weeks treatment with single-agent abiraterone and a minimum of 6 weeks treatment with abiraterone combined with dexamethasone. Previous studies have shown linear relationships between lumbar skeletal muscle and fat cross-sectional areas measured using multiple-slice computed tomography (CT) and whole-body muscle and fat mass measured using dedicated dual-energy X-ray absorptiometry (DEXA) scans (Shen et al, 2004; Mourtzakis et al, 2008). We thus were able to use CT scans performed for clinical or restaging purposes for analyses of changes in body composition. For this analysis, patients were required to have three available CT scans: a pretreatment CT for baseline assessment, a CT following a minimum of 6 weeks treatment on abiraterone alone (before initiation of dexamethasone; treatment period 1, see Supplementary Table S1) and a CT after a similar duration of treatment with combination abiraterone and dexamethasone (treatment period 2). Crosssectional areas of muscle were averaged from two consecutive CT slices at the L3 level as has been described previously (Prado et al, 2008; Antoun et al, 2010) using OsiriX version 4.0 (Pixmeo, Geneva, Switzerland) and Slice-O-Matic version 4.3 (TomoVision, Magog, QC, Canada) software. Total fat and visceral fat were measured at the L4 level using the same technique. Subcutaneous fat was manually calculated from the difference between total and visceral fat. Measurements were undertaken by three trained assessors (CP, DM, GS) and were independently reviewed by a radiologist (NT). Anthropomorphic measurements of height at baseline and weight at each assessment point were used to calculate BMI (expressed as $\mathrm{kg} \mathrm{m}^{-2}$ ).

Statistical analysis. Changes in body composition were assessed by baseline BMI status $(<25,25-30,>30)$ as the relative change in body composition on treatment was expected to vary between these baseline groups. Unlike the fixed treatment intervals used in adjuvant hormone schedules, CRPC patients receive abiraterone for highly variable periods of time. The inter-scan intervals (from start to completion of treatment, see Supplementary Table S1) therefore differ between patients, and observed changes in body composition could be similarly expected to depend on the length of treatment patients received. Thus a model-based approach was used, with selection of linear mixed regression models to account for the natural correlation among repeated measures (Verbeke and Molenberghs, 2000). The individual patient data were incorporated in this model to account for variability in scan intervals, and all results represent estimated change after 6 months on the reported treatment combination. Predictor variables were abiraterone and dexamethasone treatment, time on abiraterone, time on dexamethasone and interactions between these variables and the baseline BMI group. These interactions allowed for potentially different slopes and effects in the different BMI groups. Models were built separately for muscle, total fat, visceral fat and subcutaneous fat areas and BMI, all of which were log transformed for analysis. The mean (and 95\% confidence interval (CI)) effect estimates were derived from linear combinations of coefficients from these models at fixed time points, which were selected to represent the average length of time spent on the different treatment combinations. Two-sided $P$ values are reported, and a $P$ value $<0.05$ was considered statistically significant. Interaction $P$ values were provided to demonstrate whether the changes observed were different between the baseline BMI groups. Due to the predefined study endpoints, no adjustment for multiplicity was considered necessary (Rothman, 1990). Analyses were performed using Stata version 12 (StataCorp LP, College Station, TX, USA) by an experienced biostatistician (AMC). Pearson correlation analyses were performed using GraphPad Prism version 5.0a (Graphpad Software, San Diego, CA, USA).

\section{RESULTS}

Patient characteristics. Of the 96 patients treated with abiraterone in early clinical trials that evaluated abiraterone alone followed by abiraterone and dexamethasone at the Royal Marsden Hospital, only 55 patients were eligible for body composition analyses (Figure 1, patient characteristics described in Table 1 and Supplementary Table S2). All subsequent studies have utilised combinations of abiraterone and exogenous glucocorticoids, and this therefore represents a unique population for evaluating the effect of 'super-castration' without the confounding factors introduced by concomitant exogenous glucocorticoids. The majority of patients were of European descent (53 Caucasian, 1 Black African, 1 Black Caribbean) and 46 patients were 


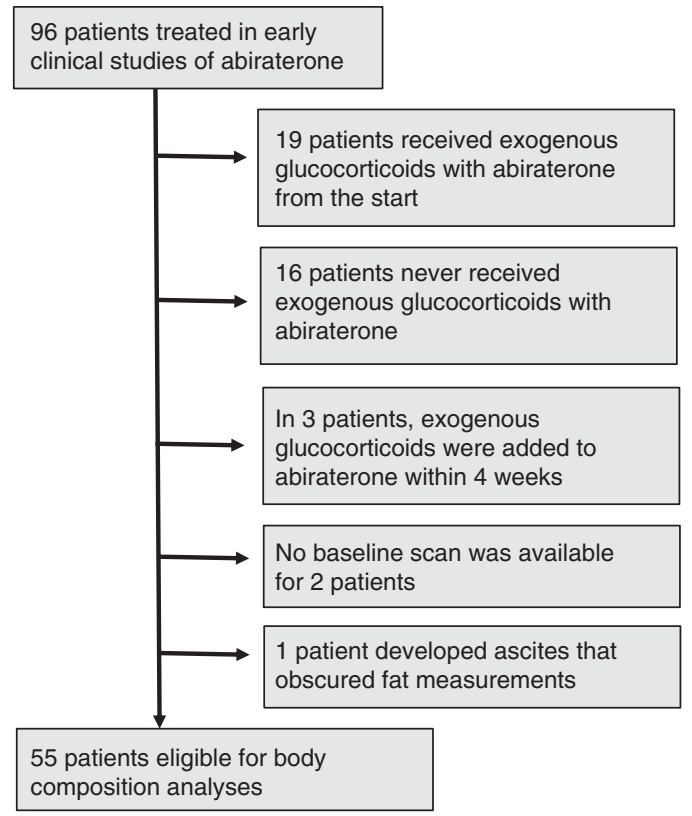

Figure 1. Selection of patients for body composition analyses.

docetaxel-naive. Before starting treatment, $10(18 \%)$ patients had a BMI $<25,26(47 \%)$ had a BMI 25-30 and 19 (35\%) had a BMI $>30$. Patients received a median of 7.5 months abiraterone alone and 5.4 months abiraterone and dexamethasone. At the CT scan evaluating change on abiraterone alone, 46 patients had a confirmed rise in PSA as defined by PSAWG I (Bubley et al, 1999), 3 (of 46) had soft-tissue progression on CT scan and three patients had progression on bone scan. Of the nine patients without PSA progression, five had toxicity and four required addition of dexamethasone following a protocol amendment (Supplementary Table S1). At the scan evaluating change on abiraterone and dexamethasone, 33 patients had a confirmed rise in PSA (7 (of 33) had soft-tissue progression on CT scan and 9 had progression on bone scan), and 22 patients had an ongoing response or stable disease and continued on study treatment.

Assessment of muscle mass and body fat using CT scans. Two software packages for evaluating body composition (OsiriX and Slice-O-Matic; Figure 2, Supplementary Figure S1) were first used to evaluate pretreatment scans by operators blinded to each other's results. There was strong correlation between area measurements with the two software techniques, with $r$-values of 0.96 for total fat, 0.94 for visceral fat and 0.80 for muscle. Both software platforms were equally user friendly, and OsiriX was selected due to individual operator choice. Baseline BMI was compared with measurements of cross-sectional areas of fat and muscle. Total fat $(r=0.85)$ and subcutaneous fat $(r=0.83)$ strongly correlated with BMI and visceral fat and muscle were less strongly correlated ( $r=0.59$ and 0.65 , respectively) (Supplementary Figure S2).

Changes in muscle and fat on treatment with abiraterone followed by abiraterone and dexamethasone. Muscle loss was observed in patients treated with single-agent abiraterone, with loss greatest in patients with a baseline BMI $>30$ (median change: BMI $<25$ : $-2.9 \%$ (95\% CI: -6.5 , + 0.8); BMI 25-30, $-2.8 \%(95 \%$ CI: $-5.1,-0.5)$; BMI $>30,-4.3 \%$ (95\% CI: $-7.1,-1.5$ ); Table 2, Figure $3 \mathrm{~A}$ ). There was no further significant change in muscle mass after the addition of dexamethasone. Surprisingly, loss of visceral fat was also observed on single-agent abiraterone. Similarly, this effect was most evident in patients with a baseline BMI > 30 who had a $19.6 \%$ (95\% CI: $-26.9,-11.6 \%)$ loss of visceral fat area (median change: BMI $<25$ : $-10.6 \%$ (95\% CI:

\begin{tabular}{|c|c|c|}
\hline Population, $\mathrm{n}=55$ & $\begin{array}{l}\text { Median } \\
\text { (range) }\end{array}$ & $\mathrm{N}(\%)$ \\
\hline \multicolumn{3}{|l|}{ Ethnicity } \\
\hline $\begin{array}{l}\text { Caucasian } \\
\text { Black African } \\
\text { Black Caribbean }\end{array}$ & & $\begin{aligned} 53 & (96) \\
1 & (2) \\
1 & (2)\end{aligned}$ \\
\hline $\begin{array}{l}\text { Gleason at diagnosis } \\
\text { Time from castration to abiraterone, years } \\
\text { Baseline PSA }\end{array}$ & $\begin{array}{l}\quad 8(4-10) \\
\text { (NA in } 3 \text { patients) } \\
3.7(0.4-13.7) \\
79(8.8-10335)\end{array}$ & \\
\hline \multicolumn{3}{|l|}{ Baseline BMI } \\
\hline $\begin{array}{l}<25 \\
25-30 \\
>30\end{array}$ & & $\begin{array}{l}10(18) \\
26(47) \\
19(35)\end{array}$ \\
\hline $\begin{array}{l}\text { Previous glucocorticoid treatment for } \\
\text { prostate cancer } \\
\text { Duration of steroids in pre-chemotherapy } \\
\text { patients, months ( } n=17 \text { ) } \\
\text { Steroid-free interval in pre-chemotherapy } \\
\text { patients, months ( } n=17 \text { ) } \\
\text { Previous docetaxel treatment } \\
\text { Age at starting abiraterone, years }\end{array}$ & $\begin{array}{l}11.2(1.0-38.0) \\
5.2(1.2-12.7) \\
68(49-86)\end{array}$ & $28(51)$ \\
\hline \multicolumn{3}{|l|}{ Metastases at baseline } \\
\hline $\begin{array}{l}\text { Bone } \\
\text { L/N } \\
\text { Visceral }\end{array}$ & & $\begin{array}{c}49(89) \\
30(55) \\
5(9)\end{array}$ \\
\hline \multicolumn{3}{|l|}{ ECOG performance status } \\
\hline $\begin{array}{l}0 \\
1 \\
\text { Overall survival, months }\end{array}$ & $\begin{array}{c}43.7 \text { (range } \\
8.5-75.7^{\mathrm{a}} \text { ) }\end{array}$ & $\begin{array}{l}37(67) \\
18(33)\end{array}$ \\
\hline 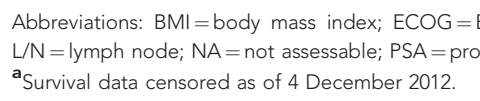 & $\begin{array}{l}\text { Cooperative Onc } \\
\text { specific antigen. }\end{array}$ & gy Group \\
\hline
\end{tabular}

$-20.9,1 \%$ ); BMI: $25-30$ : $-9.9 \%$ (95\% CI: $-16.6,-2.7 \%$ ); Table 2, Figures $3 \mathrm{~B}$ and $\mathrm{C}$ ). Loss of subcutaneous fat was less marked (Table 2, Supplementary Figure S3). In keeping with loss of fat and muscle with single-agent abiraterone, there was also a decrease in BMI, again most significant in patients with a baseline BMI > 30 ( $-8.1 \%$ (95\% CI: $-10.8,-5.4)$; Table 2, Figure 3D).

In contrast, the addition of dexamethasone led to a striking increase in central fat in all the patients regardless of baseline BMI and most notably visceral $(\mathrm{BMI}<25$ : $+23.6 \%$ (95\% CI: +9.3 , $+39.8 \%$ ), BMI 25-30: + 17.8\% (95\% CI: + 9.2, + 27.1\%), $\mathrm{BMI}>30:+27.9 \%(95 \% \mathrm{CI}:+16.9,+39.9 \%))$, with a recovery in fat to pre-abiraterone levels (Table 2, Figures $3 \mathrm{~B}$ and $\mathrm{C}$ ). The change in subcutaneous fat was again less marked (Table 2, Supplementary Figure S3). Overall, there was a significant increase in total fat $(+10.9 \%(95 \% \mathrm{CI}:+0.8,+22 \%))$ by completion of both treatment periods in patients with a baseline BMI $<25$ (Table 2). After the addition of dexamethasone, all groups experienced a marked increase in BMI $(<25: 6.0 \%(2.0,10.2)$; 25-30: 5.8\% (3.3, 8.3); > 30: 3.8\% (1.0, 6.8)). However, over both treatment periods there was a median increase in BMI of $+3.8 \%$ for patients with a baseline BMI $<25(95 \% \mathrm{CI}$ : $-0.2,8.0)$ and 
A

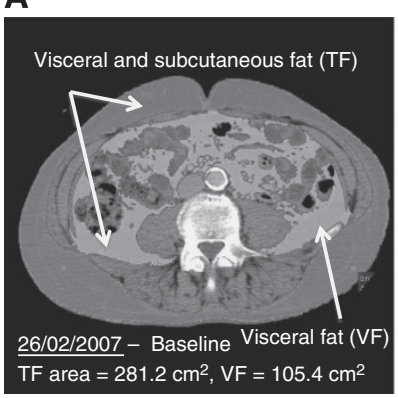

D

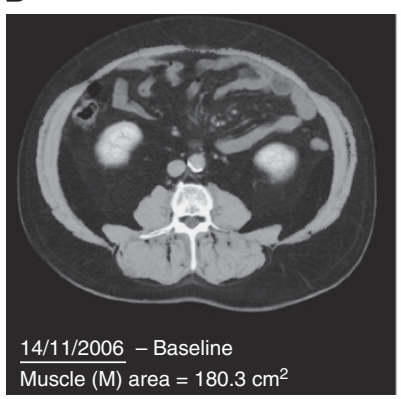

B

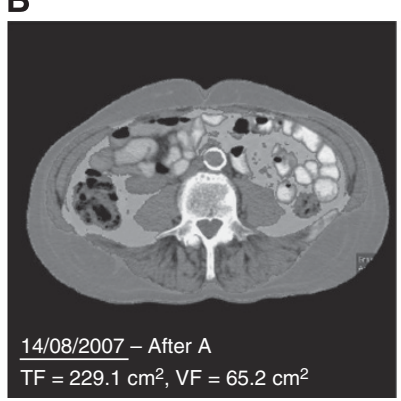

E

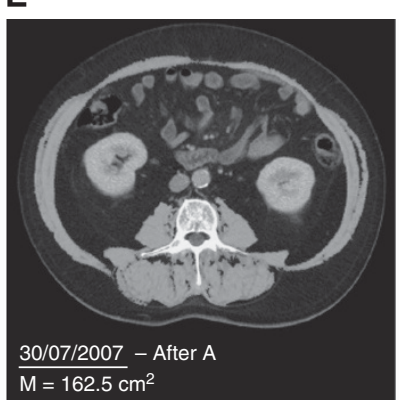

C

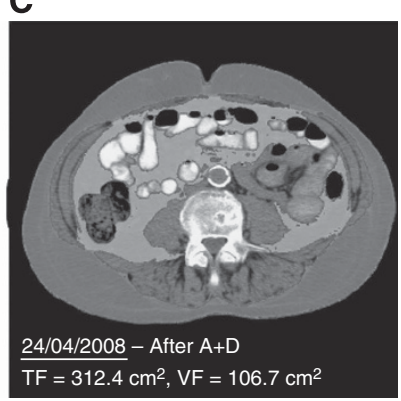

F

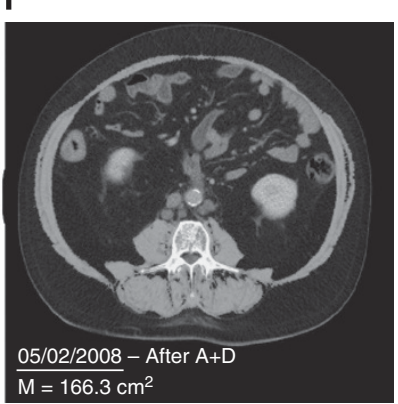

Figure 2. Analysis of body composition using OsiriX software: (A) total (visceral and subcutaneous) and visceral fat analysis at baseline, (B) after abiraterone and $(\mathbf{A})(\mathbf{C})$ after abiraterone plus dexamethasone; $(\mathbf{A}+\mathbf{D})$ muscle analysis, including psoas, paravertebral and abdominal muscles at (D) baseline, (E) after abiraterone and (F) after abiraterone plus dexamethasone.

Table 2. Changes in fat and muscle following treatment with abiraterone (abi) and after addition of dexamethasone (dexa) to abiraterone

\begin{tabular}{|c|c|c|c|c|c|c|c|c|c|}
\hline & & \multicolumn{2}{|c|}{$\begin{array}{c}\text { Change on abi from } \\
\text { baseline }\end{array}$} & \multicolumn{3}{|c|}{ Change on abi + dexa from abi alone } & \multicolumn{3}{|c|}{ Change on abi + dexa from baseline } \\
\hline & $\begin{array}{l}\text { Relative change at } \\
6 \text { months }(95 \% \mathrm{Cl})\end{array}$ & $\boldsymbol{P}$-value & Int. $p$ & $\begin{array}{l}\text { Relative change at } \\
12 \text { months }(95 \% \mathrm{Cl})\end{array}$ & $\boldsymbol{P}$-value & Int. $p$ & $\begin{array}{l}\text { Relative change at } \\
12 \text { months }(95 \% \mathrm{Cl})\end{array}$ & $\boldsymbol{P}$-value & Int. $p$ \\
\hline \multicolumn{10}{|l|}{ Muscle } \\
\hline $\begin{array}{l}\mathrm{BMI}<25 \\
\mathrm{BMI} \\
25-30 \\
\mathrm{BMI}>30\end{array}$ & $\begin{array}{c}0.971(0.935,1.008) \\
0.972(0.949,0.995) \\
0.957(0.929,0.985)\end{array}$ & $\begin{array}{l}0.1278 \\
0.0191 \\
\\
0.0029\end{array}$ & 0.6840 & $\begin{array}{l}1.016(0.978,1.055) \\
1.005(0.982,1.029) \\
0.990(0.963,1.017)\end{array}$ & $\begin{array}{l}0.4132 \\
0.6584 \\
0.4578\end{array}$ & 0.5047 & $\begin{array}{l}0.987(0.949,1.026) \\
0.977(0.953,1.001) \\
0.947(0.917,0.977)\end{array}$ & $\begin{array}{l}0.4969 \\
0.0653 \\
0.0007\end{array}$ & 0.5875 \\
\hline \multicolumn{10}{|c|}{ Total fat } \\
\hline $\begin{array}{l}\mathrm{BMl}<25 \\
\mathrm{BMI} \\
25-30 \\
\mathrm{BMI}>30\end{array}$ & $\begin{array}{c}0.935(0.852,1.026) \\
0.941(0.888,0.998) \\
0.845(0.786,0.908)\end{array}$ & $\begin{array}{l}0.1549 \\
0.0426 \\
<0.0001\end{array}$ & 0.0573 & $\begin{array}{l}1.186(1.081,1.302) \\
1.125(1.062,1.191) \\
1.211(1.131,1.296)\end{array}$ & $\begin{array}{l}0.0003 \\
0.0001 \\
<0.0001\end{array}$ & 0.2447 & $\begin{array}{c}1.109(1.008,1.220) \\
1.059(0.997,1.125) \\
1.023(0.946,1.106)\end{array}$ & $\begin{array}{l}0.0341 \\
0.0647 \\
0.5725\end{array}$ & 0.1068 \\
\hline \multicolumn{10}{|c|}{ Visceral fat } \\
\hline $\begin{array}{l}\mathrm{BMI}<25 \\
\mathrm{BMI} \\
25-30 \\
\mathrm{BMI}>30\end{array}$ & $\begin{array}{c}0.894(0.791,1.010) \\
0.901(0.834,0.973) \\
0.804(0.731,0.884)\end{array}$ & $\begin{array}{l}0.0725 \\
0.0082 \\
<0.0001\end{array}$ & 0.1640 & $\begin{array}{l}1.236(1.093,1.398) \\
1.178(1.092,1.271) \\
1.279(1.169,1.399)\end{array}$ & $\begin{array}{c}0.0007 \\
<0.0001 \\
<0.0001\end{array}$ & 0.3832 & $\begin{array}{l}1.105(0.973,1.253) \\
1.062(0.980,1.150) \\
1.028(0.928,1.140)\end{array}$ & $\begin{array}{l}0.1230 \\
0.1431 \\
0.5931\end{array}$ & 0.3160 \\
\hline \multicolumn{10}{|c|}{ Subcutaneous fat } \\
\hline $\begin{array}{l}\mathrm{BMl}<25 \\
\mathrm{BMl} \\
25-30 \\
\mathrm{BMI}>30\end{array}$ & $\begin{array}{l}0.980(0.864,1.111) \\
0.975(0.901,1.056) \\
0.884(0.802,0.974)\end{array}$ & $\begin{array}{l}0.7510 \\
0.5379 \\
0.0131\end{array}$ & 0.2540 & $\begin{array}{l}1.130(0.996,1.282) \\
1.049(0.970,1.134) \\
1.164(1.061,1.277)\end{array}$ & $\begin{array}{l}0.0581 \\
0.2326 \\
0.0013\end{array}$ & 0.2180 & $\begin{array}{l}1.107(0.972,1.261) \\
1.023(0.942,1.110) \\
1.029(0.925,1.143)\end{array}$ & $\begin{array}{l}0.1242 \\
0.5884 \\
0.6005\end{array}$ & 0.1562 \\
\hline \multicolumn{10}{|l|}{ BMI } \\
\hline $\begin{array}{l}<25 \\
25-30 \\
>30\end{array}$ & $\begin{array}{c}0.979(0.943,1.017) \\
0.975(0.952,0.998) \\
0.919(0.892,0.946)\end{array}$ & $\begin{array}{c}0.2789 \\
0.0362 \\
<0.0001\end{array}$ & 0.0043 & $\begin{array}{l}1.060(1.020,1.102) \\
1.058(1.033,1.083) \\
1.038(1.010,1.068)\end{array}$ & $\begin{array}{l}0.0027 \\
<0.0001 \\
0.0084\end{array}$ & 0.5419 & $\begin{array}{c}1.038(0.998,1.080) \\
1.031(1.006,1.057) \\
0.954(0.924,0.985)\end{array}$ & $\begin{array}{l}0.0619 \\
0.0154 \\
0.0040\end{array}$ & 0.0535 \\
\hline
\end{tabular}


A
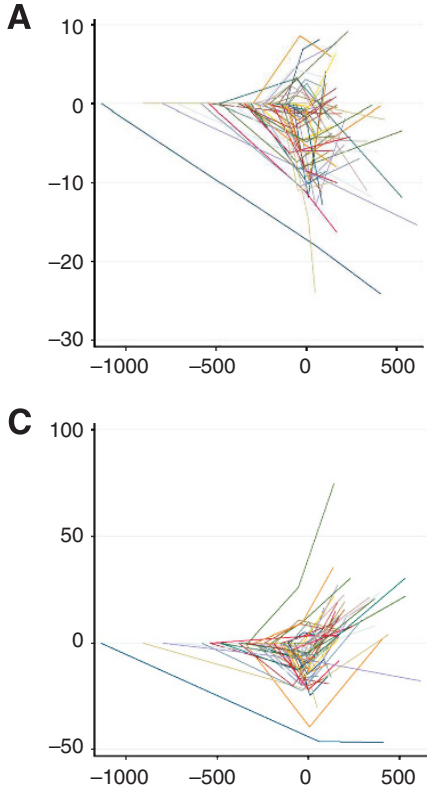
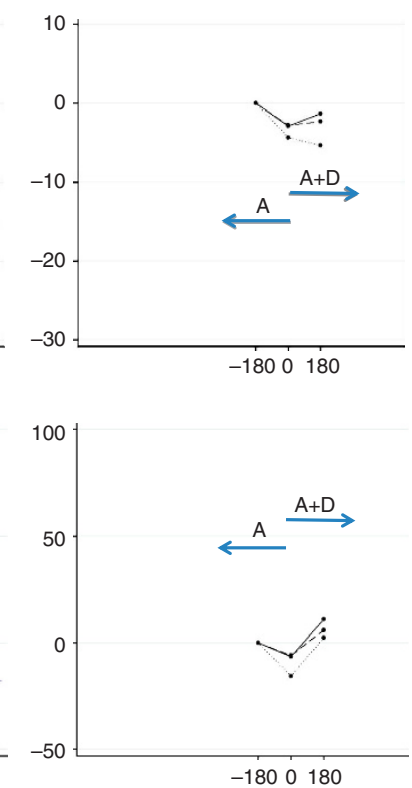

B

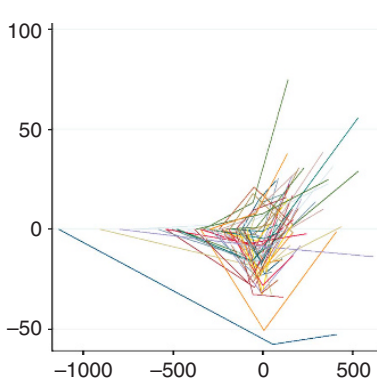

D

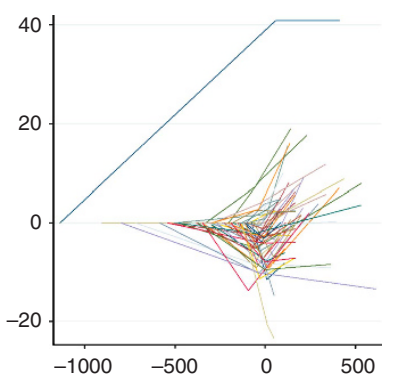

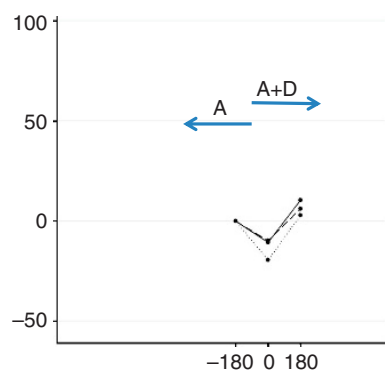

$-1800180$

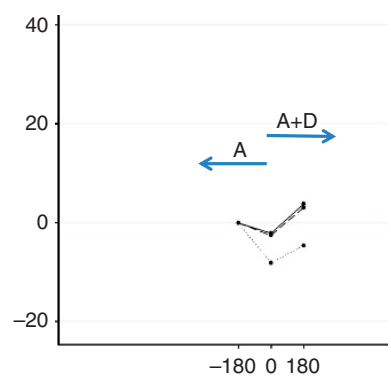

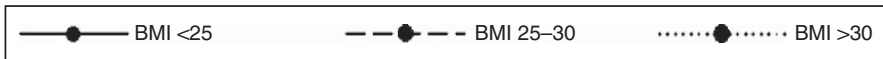

Figure 3. Percentage change in (A) muscle area, (B) visceral fat, $(\mathbf{C})$ total fat and (D) BMI on abiraterone (A) and abiraterone plus dexamethasone $(A+D)$. Modeled individual patient data are presented on the left, and median trend divided by BMI on the right. Solid blue arrows indicate the phase of treatment.

$3.1 \%$ in patients with a baseline BMI $25-30$ (95\% CI: 0.6, 5.7; Table 2, Figure 3E). In contrast, there was a $4.6 \%$ decrease $(95 \% \mathrm{CI}$ : $-7.6,-1.5)$ in BMI in patients with a baseline BMI $>30$.

Loss of fat and muscle shows stabilization on castration before abiraterone treatment. In view of the finding of muscle and fat loss with abiraterone, we sought to exclude whether this was ongoing secondary to castration or induced by initiation of abiraterone. We identified a subset of seven men with CT scans performed a minimum of 6 months before commencing abiraterone and who had muscle loss (range: $2.1-17.1 \%$ reduction in area) on single-agent abiraterone. Pretreatment CT scans were performed a median of 9.7 months earlier (range: 6.5-15.1 months). No patient had muscle loss in this interval (Figure 4), and there was no consistent effect on visceral or subcutaneous fat measurements. Moreover, in the entire cohort there was no correlation between loss of muscle or fat on abiraterone and time from commencing castration (Supplementary Figure S4).

\section{DISCUSSION}

This is the first study to report muscle loss in castrate men caused by increasing suppression of serum androgens to a 'super-castrate' range by abiraterone. This is notable because a significant proportion of patients remain on abiraterone for many months and the prevalence and risks of sarcopenia are likely to be underestimated, despite the potential impact on patients' quality of life. Side-effects associated with androgen suppression, including hot flushes and testicular atrophy, have been reported previously (Attard et al, 2008; Ryan et al, 2010), but changes in body composition have, to date, not been studied. Patients with a pretreatment $\mathrm{BMI}>30$ experienced the most significant loss of muscle mass. The finding that single-agent abiraterone resulted in loss of visceral fat in addition to muscle, with a corresponding decrease in BMI, was unexpected. Small cohort studies utilizing CT scans have previously reported conflicting effects on visceral fat

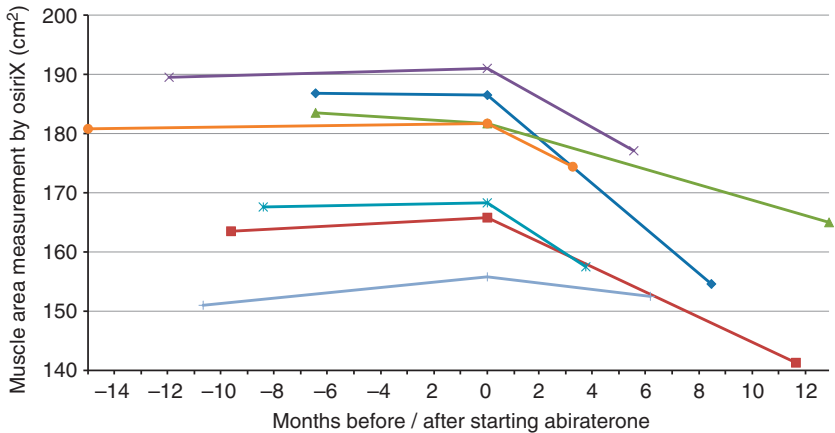

Figure 4. Changes in muscle before and after starting abiraterone $(n=7)$.

with androgen deprivation. A study in 32 men commencing firstline androgen deprivation suggested no change after 48 weeks on treatment (Smith et al, 2002), whereas a $22 \%$ increase in visceral abdominal fat was reported in 26 men over the first 12 months of androgen deprivation (Hamilton et al, 2011). Most studies of sarcopenia in prostate cancer utilize DEXA scans and therefore cannot identify changes in visceral fat.

No additional loss of muscle was observed on addition of dexamethasone to abiraterone. Although this is likely to be a result of a plateau in muscle loss as has also been observed in men treated with initial androgen-deprivation therapy (Lee et al, 2005; Smith et al, 2012), we cannot exclude the possibility that glucocorticoids initiated with abiraterone would protect against muscle loss. This could be a consideration for trials utilizing lower dose of exogenous glucocortiocoids. Sarcopenia could occur secondary to disease progression, but the absence of significant changes in progressing patients before initiation of abiraterone (Figure 4), the plateau in muscle loss maintained after addition of dexamethasone and the fact that the majority of patients had a rising PSA in the absence of radiological progression at evaluation for changes on single-agent abiraterone (Supplementary Table S1) suggest that disease 
progression cannot explain our findings. Also, there was no significant gastro-intestinal toxicity with abiraterone that could explain the loss of muscle and fat observed. Conversely and as anticipated, there was gain of central fat, most notably visceral, and BMI on addition of exogenous glucocorticoid ( $0.5 \mathrm{mg}$ dexamethasone, equivalent to $5-7.5 \mathrm{mg}$ prednisone). In this study, we only observed a significant gain in fat after completion of both study periods compared with pre-abiraterone in patients with a BMI $<25$. In current routine clinical practice, glucocorticoids are initiated with abiraterone, and this could change the extent of fat gain.

These data were obtained in an unplanned post-hoc analysis and must be regarded as exploratory and hypothesis-generating. The sample size limited the statistical power for subgroup analyses. The variability in treatment duration and imaging was accounted for in the statistical model. However, an important potential confounder was the previous exposure to glucocorticoid treatment in half of the subjects. The impact of such treatment would only be explored through further analysis of larger patient groups. Abiraterone has now been extensively evaluated in Phase I, II and III clinical trials, and there are no reports of an association with an increase in cardio-metabolic events. However, overall these data introduce important considerations on the long-term implications of profound androgen suppression. Importantly, they should instigate further in-depth evaluation of changes in body composition in a larger cohort of patients using restaging CT scans obtained in the post- and pre-chemotherapy abiraterone Phase III studies (COU301, COU-302), ongoing clinical studies of other C17,20-lyase inhibitors and prospective Phase IV studies. The incidence of sarcopenia secondary to other novel hormonal manipulations, including for example enzalutamide recently shown to improve overall survival of CRPC patients (Scher et al, 2012), should also be evaluated.

\section{ACKNOWLEDGEMENTS}

The authors are employees of the Section of Medicine that is supported by a Cancer Research UK programme grant and an Experimental Cancer Medical Centre (ECMC) grant from Cancer Research UK and the Department of Health (Ref: C51/A7401). GA is also supported by a Cancer Research UK Clinician Scientist Fellowship. We acknowledge NHS funding to the Royal Marsden NIHR Biomedical Research Centre. The clinical studies were sponsored by Cougar Biotechnology, now a unit of Johnson and Johnson, who were, however, not involved in this post-hoc analysis.

\section{CONFLICT OF INTEREST}

Abiraterone acetate was developed at The Institute of Cancer Research, which therefore has a commercial interest in the development of this agent. CP received lecture fees from SanofiAventis and travel support from Sanofi-Aventis and Janssen-Cilag. JSdB received consulting fees from Ortho Biotech Oncology Research and Development (a unit of Cougar Biotechnology), consulting fees and travel support from Amgen, Astellas, AstraZeneca, Boehringer Ingelheim, Bristol-Myers Squibb, Dendreon, Enzon, Exelixis, Genentech, GlaxoSmithKline, Medivation, Merck, Novartis, Pfizer, Roche, Sanofi-Aventis, Supergen, and Takeda, and grant support from AstraZeneca and Genentech. GA received consulting fees and travel support from Janssen-Cilag, Veridex, Roche/Ventana, Novartis, Astellas, Medivation and Millennium Pharmaceuticals, lecture fees from Janssen-Cilag, Ipsen, Takeda and Sanofi-Aventis, and grant support from
AstraZeneca and Genentech. GA is on The ICR rewards to inventors list of abiraterone acetate.

\section{REFERENCES}

Antoun S, Baracos VE, Birdsell L, Escudier B, Sawyer MB (2010) Low body mass index and sarcopenia associated with dose-limiting toxicity of sorafenib in patients with renal cell carcinoma. Ann Oncol 21(8): 1594-1598.

Attard G, Reid AH, A'Hern R, Parker C, Oommen NB, Folkerd E, Messiou C, Molife LR, Maier G, Thompson E, Olmos D, Sinha R, Lee G, Dowsett M, Kaye SB, Dearnaley D, Kheoh T, Molina A, de Bono JS (2009) Selective inhibition of CYP17 with abiraterone acetate is highly active in the treatment of castration-resistant prostate cancer. J Clin Oncol 27(23): 3742-3748.

Attard G, Reid AH, Auchus RJ, Hughes BA, Cassidy AM, Thompson E, Oommen NB, Folkerd E, Dowsett M, Arlt W, de Bono JS (2012) Clinical and biochemical consequences of CYP17A1 inhibition with abiraterone given with and without exogenous glucocorticoids in castrate men with advanced prostate cancer. J Clin Endocrinol Metab 97(2): 507-516.

Attard G, Reid AH, Yap TA, Raynaud F, Dowsett M, Settatree S, Barrett M, Parker C, Martins V, Folkerd E, Clark J, Cooper CS, Kaye SB, Dearnaley D, Lee G, de Bono JS (2008) Phase I clinical trial of a selective inhibitor of CYP17, abiraterone acetate, confirms that castration-resistant prostate cancer commonly remains hormone driven. J Clin Oncol 26(28): 4563-4571.

Basaria S, Bhasin S (2012) Targeting the skeletal muscle-metabolism axis in prostate-cancer therapy. N Engl J Med 367(10): 965-967.

Bubley GJ, Carducci M, Dahut W, Dawson N, Daliani D, Eisenberger M, Figg WD, Freidlin B, Halabi S, Hudes G, Hussain M, Kaplan R, Myers C, Oh W, Petrylak DP, Reed E, Roth B, Sartor O, Scher H, Simons J, Sinibaldi V, Small EJ, Smith MR, Trump DL, Vollmer R, Wilding G (1999) Eligibility and response guidelines for phase II clinical trials in androgenindependent prostate cancer: recommendations from the Prostate-Specific Antigen Working Group. J Clin Oncol 17(11): 3461-3467.

Carden CP, Raynaud FI, Jones RL, Riggs SB, Martins V, Oommen N, McIntosh D, Lee G, De Bono JS, Kabbinavar FF (2008) Crossover pharmacokinetics (PK) study to assess oral administration of abiraterone acetate capsule and tablet formulations in fasted and fed states in patients with prostate cancer. J Clin Oncol 26(suppl): abstr 5168.

de Bono JS, Logothetis CJ, Molina A, Fizazi K, North S, Chu L, Chi KN, Jones RJ, Goodman Jr. OB, Saad F, Staffurth JN, Mainwaring P, Harland S, Flaig TW, Hutson TE, Cheng T, Patterson H, Hainsworth JD, Ryan CJ, Sternberg CN, Ellard SL, Flechon A, Saleh M, Scholz M, Efstathiou E, Zivi A, Bianchini D, Loriot Y, Chieffo N, Kheoh T, Haqq CM, Scher HI (2011) Abiraterone and increased survival in metastatic prostate cancer. $\mathrm{N} \mathrm{Engl} \mathrm{J}$ Med 364(21): 1995-2005.

Fearon K, Strasser F, Anker SD, Bosaeus I, Bruera E, Fainsinger RL, Jatoi A, Loprinzi C, MacDonald N, Mantovani G, Davis M, Muscaritoli M, Ottery F, Radbruch L, Ravasco P, Walsh D, Wilcock A, Kaasa S, Baracos VE (2011) Definition and classification of cancer cachexia: an international consensus. Lancet Oncol 12(5): 489-495.

Galvao DA, Taaffe DR, Spry N, Joseph D, Newton RU (2010) Combined resistance and aerobic exercise program reverses muscle loss in men undergoing androgen suppression therapy for prostate cancer without bone metastases: a randomized controlled trial. J Clin Oncol 28(2): 340-347.

Hamilton EJ, Gianatti E, Strauss BJ, Wentworth J, Lim-Joon D, Bolton D, Zajac JD, Grossmann M (2011) Increase in visceral and subcutaneous abdominal fat in men with prostate cancer treated with androgen deprivation therapy. Clin Endocrinol (Oxf) 74(3): 377-383.

Lan NC, Graham B, Bartter FC, Baxter JD (1982) Binding of steroids to mineralocorticoid receptors: implications for in vivo occupancy by glucocorticoids. J Clin Endocrinol Metab 54(2): 332-342.

Lee H, McGovern K, Finkelstein JS, Smith MR (2005) Changes in bone mineral density and body composition during initial and long-term gonadotropin-releasing hormone agonist treatment for prostate carcinoma. Cancer 104(8): 1633-1637.

Mourtzakis M, Prado CM, Lieffers JR, Reiman T, McCargar LJ, Baracos VE (2008) A practical and precise approach to quantification of body composition in cancer patients using computed tomography images acquired during routine care. Appl Physiol Nutr Metab 33(5): 997-1006. 
Prado CM, Lieffers JR, McCargar LJ, Reiman T, Sawyer MB, Martin L, Baracos VE (2008) Prevalence and clinical implications of sarcopenic obesity in patients with solid tumours of the respiratory and gastrointestinal tracts: a population-based study. Lancet Oncol 9(7): 629-635.

Reid AH, Attard G, Danila DC, Oommen NB, Olmos D, Fong PC, Molife LR, Hunt J, Messiou C, Parker C, Dearnaley D, Swennenhuis JF, Terstappen LW, Lee G, Kheoh T, Molina A, Ryan CJ, Small E, Scher HI, de Bono JS (2010) Significant and sustained antitumor activity in post-docetaxel, castration-resistant prostate cancer with the CYP17 inhibitor abiraterone acetate. J Clin Oncol 28(9): 1489-1495.

Rothman KJ (1990) No adjustments are needed for multiple comparisons. Epidemiology 1(1): 43-46.

Ryan CJ, Smith MR, de Bono JS, Molina A, Logothetis CJ, de Souza P, Fizazi K, Mainwaring P, Piulats JM, Ng S, Carles J, Mulders PF, Basch E, Small EJ, Saad F, Schrijvers D, Van Poppel H, Mukherjee SD, Suttmann H, Gerritsen WR, Flaig TW, George DJ, Yu EY, Efstathiou E, Pantuck A, Winquist E, Higano CS, Taplin ME, Park Y, Kheoh T, Griffin T, Scher HI, Rathkopf DE (2013) Abiraterone in metastatic prostate cancer without previous chemotherapy. N Engl J Med 368(2): 138-148.

Ryan CJ, Smith MR, Fong L, Rosenberg JE, Kantoff P, Raynaud F, Martins V, Lee G, Kheoh T, Kim J, Molina A, Small EJ (2010) Phase I clinical trial of the CYP17 inhibitor abiraterone acetate demonstrating clinical activity in patients with castration-resistant prostate cancer who received prior ketoconazole therapy. J Clin Oncol 28(9): 1481-1488.

Scher HI, Fizazi K, Saad F, Taplin ME, Sternberg CN, Miller K, de Wit R, Mulders P, Chi KN, Shore ND, Armstrong AJ, Flaig TW, Flechon A, Mainwaring P, Fleming M, Hainsworth JD, Hirmand M, Selby B, Seely L, de Bono JS (2012) Increased survival with enzalutamide in prostate cancer after chemotherapy. N Engl J Med 367(13): 1187-1197.
Segal RJ, Reid RD, Courneya KS, Malone SC, Parliament MB, Scott CG, Venner PM, Quinney HA, Jones LW, D'Angelo ME, Wells GA (2003) Resistance exercise in men receiving androgen deprivation therapy for prostate cancer. J Clin Oncol 21(9): 1653-1659.

Shen W, Punyanitya M, Wang Z, Gallagher D, St-Onge MP, Albu J, Heymsfield SB, Heshka S (2004) Total body skeletal muscle and adipose tissue volumes: estimation from a single abdominal cross-sectional image. J Appl Physiol 97(6): 2333-2338.

Smith MR, Finkelstein JS, McGovern FJ, Zietman AL, Fallon MA, Schoenfeld DA, Kantoff PW (2002) Changes in body composition during androgen deprivation therapy for prostate cancer. J Clin Endocrinol Metab 87(2): 599-603.

Smith MR, Saad F, Egerdie B, Sieber PR, Tammela TL, Ke C, Leder BZ, Goessl C (2012) Sarcopenia during androgen-deprivation therapy for prostate cancer. J Clin Oncol 30(26): 3271-3276.

Venkitaraman R, Thomas K, Huddart RA, Horwich A, Dearnaley DP, Parker CC (2008) Efficacy of low-dose dexamethasone in castration-refractory prostate cancer. BJU Int 101(4): 440-443.

Verbeke G, Molenberghs G (2000) Linear Mixed Models for Longitudinal Data. Springer: New York, NY, USA.

Vermeulen A, Goemaere S, Kaufman JM (1999) Testosterone, body composition and aging. J Endocrinol Invest 22(5 Suppl): 110-116.

This work is published under the standard license to publish agreement. After 12 months the work will become freely available and the license terms will switch to a Creative Commons AttributionNonCommercial-Share Alike 3.0 Unported License.

Supplementary Information accompanies this paper on British Journal of Cancer website (http://www.nature.com/bjc) 